\title{
Dynamic response of a semi-submersible floating offshore wind turbine under flooded column damage
}

\author{
Kan Zheng ${ }^{3, \text { a, Wei Shi }}{ }^{1,2,3,4, b}$, Nianxin Ren 1,3, c \\ ${ }^{1}$ State Key Laboratory of Coastal and Offshore Engineering, Dalian University of Technology, Dalian, \\ Liaoning, 116024, China \\ 2Ocean Engineering Joint Research Center of DUT-UWA, Dalian University of Technology, Dalian, \\ Liaoning, 116024, China \\ ${ }^{3}$ Deepwater Engineering Research Center, Dalian University of Technology, Dalian, \\ Liaoning,116024, China \\ ${ }^{4}$ Key Laboratory of Ocean Energy Utilization and Energy Conservation of Ministry of Education, \\ Dalian, 116024, China
}

a zhengkan1993@mail.dlut.edu.cn, b weishi@dlut.edu.cn, c rennianxin@dlut.edu.cn

\begin{abstract}
Keywords: dynamic response, flooded column damage, semi-submersible, floating wind turbine Abstract. One of the main aspect of floating offshore wind turbine (FOWT) operating in normal is the safety of its cabin. The ballast water in cabin is closely related to the stability of FOWT. The dynamic response of the motion and the mooring lines force will be changed once its flooded column damage. In this paper, three different types of flooded column damage of OC4 DeepCwind semi-submersible floating offshore wind turbine are set and the performance of it under flooded column damage has been investigated. Simulation result shows that flooded column damaged has a vital effect on platform stability. The result of this paper could offer reference for FOWT's design and optimization.
\end{abstract}

\section{Introduction}

In recent years, wind energy has been the fastest-growing renewable resource. As an important source in the wind energy industry, offshore winds have been increasingly developed in wind power generation. Compared to onshore wind power, offshore wind power has several advantages over onshore wind power. First, offshore wind sites generally produce stronger winds with less turbulence on average because the sea surface is considerably smoother than the land surface. Second, the effects of noise and visual pollution from these sites on humans are negligible because of their distance from populated areas. Finally, in most countries, the sea is owned by the government rather than private landlords, which allows for the development of large offshore wind farms [1]. Hence, FOWT is widely investigated in the world due to its vast potential for offshore wind power generation. FOWTs are generally divided into three categories: tension leg platform (TLP), Spar and semi-submersible. As compared to spar type and TLP wind turbines, the advantages of semi-submersible wind turbines include, but are not limited to, 1) greater flexibility in terms of varying sea bed conditions and drafts and 2) significantly reduced installation costs due to their simpler installation, with full assembly at dock [2].

Huijs [3] concentrated on GustoMSC Tri-Floater semi-submersible wind turbine and found that the mooring system has a considerable effect on the floating stability. Deng [4] conducted a numerical simulation for a 5WM floating wind turbine by using Sesam software to investigate how three main factors, including the distance between pontoons, the radius of pontoons and the height of freeboard, influence the stability of platforms. Wu [5] focused on a semi-submersible wind turbine which is developed by Institute of Ocean Renewable Energy System (IORS) of Harbin Engineering University (HEU) and mainly investigates its responses under storm condition. According to the performance of surge motion, pitch motion and mooring tension in time history, the reliability of the semi-submersible wind turbine under storm condition is to be proved. Li [6] investigated the mooring system of ship under typhoon state. The result shows that the The better the elasticity of the mooring line is, the smaller the tensions on the line. Zhang [7] designed a triple-column semi-submersible 
floating wind turbine and analysis on intact stability and damaged stability. The result showed that when one cabin or two flooded column damage, the floating wind turbine will not overturn.

In this paper, OC4 DeepCwind semi-submersible FOWT is investigated in the time domain under its base columns damaged. The dynamic response of different types of the base columns damage is simulated under two different design load cases. A series of comparison between different types of damage in six freedom degree and mooring line force.

\section{The definition of model of OC4 DeepCwind semi-submersible FOWT}

\section{Description of the OC4 DeepCwind Semi-submersible system}

The phase II of the Offshore Code Comparison Collaboration Continued (OC4) project, operated under IEA Wind Task 30, has defined the semisubmersible floating system [8] for the National Renewable Energy Laboratory (NREL) offshore 5-MW baseline wind turbine [9]. According to the definition of OC4 DeepCwind system, the height of tower is $87.6 \mathrm{~m}$ and the total mass is $249718 \mathrm{~kg}$. The platform which concludes the main column (MC) and two sets of three offset columns (Upper columns and Base columns). The offset columns which contain ballast water are shown in Figure 1 and Figure 2. Columns are connected by braces and pontoons. The main parameters of OC4 DeepCwind semisubmersible FOWT are listed in Table 1. In this paper, numerical simulation for dynamic response of OC4 DeepCwind system is carried out by hydrodynamic software package ANSYS-AQWA.

Table 1 The main parameters of OC4 DeepCwind semi-submersible floating offshore wind turbine

\begin{tabular}{ll}
\hline Parameters & Value \\
\hline Wind turbine & NREL $5 M W$ \\
Hub and Nacelle mass & $350 \mathrm{t}$ \\
Tower height/mass & $87.6 \mathrm{~m} / 249.715 \mathrm{t}$ \\
\hline Platform & OC4 DeepCwind \\
\hline Platform mass, including ballast & $1.3473 \mathrm{E}+7 \mathrm{~kg}$ \\
CM location below SWL & $13.46 \mathrm{~m}$ \\
Platform roll/pitch/yaw inertia about CM & $6.827 \mathrm{E}+9 / 6.827 \mathrm{E}+9 / 1.226 \mathrm{E}+10 \mathrm{~kg}-\mathrm{m}^{2}$ \\
Diameter of main column & $6.5 \mathrm{~m}$ \\
Diameter of offset (upper) columns & $12 \mathrm{~m}$ \\
Diameter of base columns & $24 \mathrm{~m}$ \\
Diameter of pontoons and cross braces & $1.6 \mathrm{~m}$ \\
Depth of platform base below SWL (total draft) & $20 \mathrm{~m}$ \\
Mooring lines & Catenary \\
Depth to Fairleads Below SWL & $14 \mathrm{~m}$ \\
Unstretched Mooring Line Length & $835.5 \mathrm{~m}$ \\
Radius to Fairleads from Platform Centerline & $40.868 \mathrm{~m}$ \\
\hline
\end{tabular}

The numerical model of OC4 DeepCwind semi-submersible system

The OC4 DeepCwind Semi-submersible system is modelled as rigid body. ANSYS-AQWA soft package is chosen to simulate the OC4 DeepCwind semi-submersible FOWT in the condition of coupled wind and wave. The total mass and inertia of turbine and tower is transferred to the mass point of platform according to parallel axis theorem The aerodynamic loads on both the wind turbine rotor are simplified as external force based on the design data of the NREL 5MW wind turbine. The data of wind speed and thrust force is shown in Figure 3. 


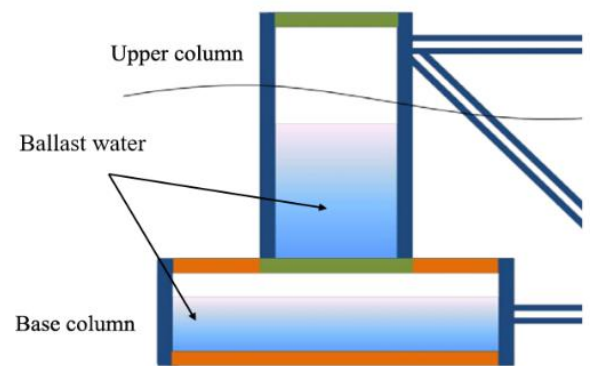

Figure 1 Side view of platform (columns and

DeepCwind ballast water distribution)

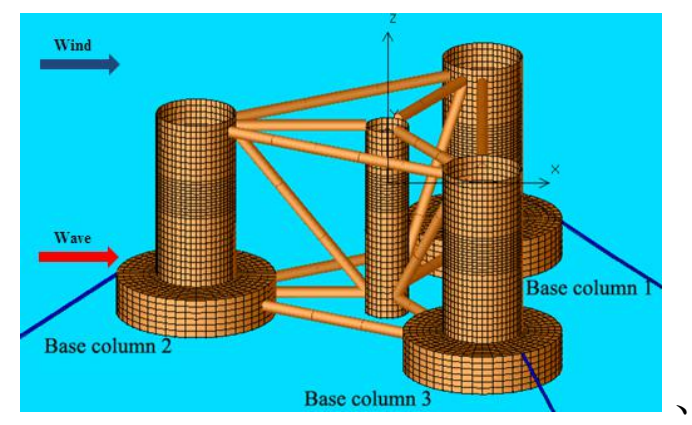

Figure 2 Numerical model of OC4 semi-submersible floating system

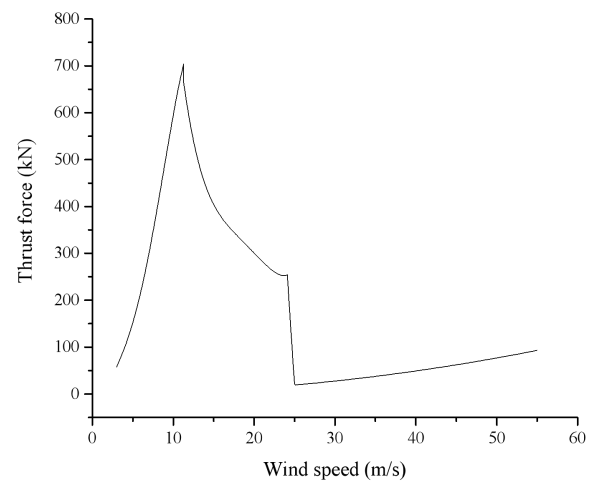

Figure 3 Thrust force and wind speed relationship of NREL 5MW wind turbine

\section{Design load cases and numerical results}

\section{Types of OC4 DeepCwind base columns damage}

Considering complicated sea condition, the stability of platform is significant to stable operation of offshore wind turbine. As for FOWT, the stability of platform mainly depends on its mooring system and ballast water in its cabin. Once flooded column damaged, the platform will be tilted even overturn. In this study, three different types of base columns damaged are set to simulate: 1\# base column damaged, $2 \#$ base column damaged and 1\#\&3\#base column damaged. No misalignment is considered in this study.

Load Case 1: constant wind and regular wave sea condition

Considering the rated wind of NREL-5MW wind turbine, typical condition is selected as the coupled rated wind speed $(11.4 \mathrm{~m} / \mathrm{s}$ ) and corresponding regular wave sea case(wave height is $3 \mathrm{~m}$, period is $10 \mathrm{~s})$.

Table 2 The dynamic motion of OC4 semi-submersible FOWT in Load Case 1

\begin{tabular}{llcccc}
\hline & & Normal & 1\# Damaged & 2\# Damaged & 1\#\&3\# Damaged \\
\hline \multirow{2}{*}{ Surge } & Mean $(\mathrm{m})$ & 6.71 & 4.18 & 13.08 & 1.20 \\
& STD & 0.50 & 0.47 & 0.51 & 0.47 \\
Sway & Mean(m) & 0.15 & -4.29 & 0.17 & 0.15 \\
& STD & 0.08 & 0.11 & 0.12 & 0.11 \\
Heave & Mean(m) & -10.48 & -8.50 & -8.87 & -5.42 \\
& STD & 0.47 & 0.20 & 0.24 & 0.17 \\
Roll & Mean $\left(^{\circ}\right)$ & 0.00 & -7.54 & 0.00 & 0.00 \\
& STD & 0.04 & 0.09 & 0.00 & 0.03 \\
Pitch & Mean $\left({ }^{\circ}\right)$ & 2.27 & -12.81 & 9.63 & -5.90 \\
& STD & 4.94 & 0.35 & 0.28 & 0.34 \\
Yaw & Mean $\left({ }^{\circ}\right)$ & 0.00 & 1.35 & 0.03 & -0.03 \\
& STD & 0.00 & 0.23 & 0.03 & 0.03 \\
\hline
\end{tabular}



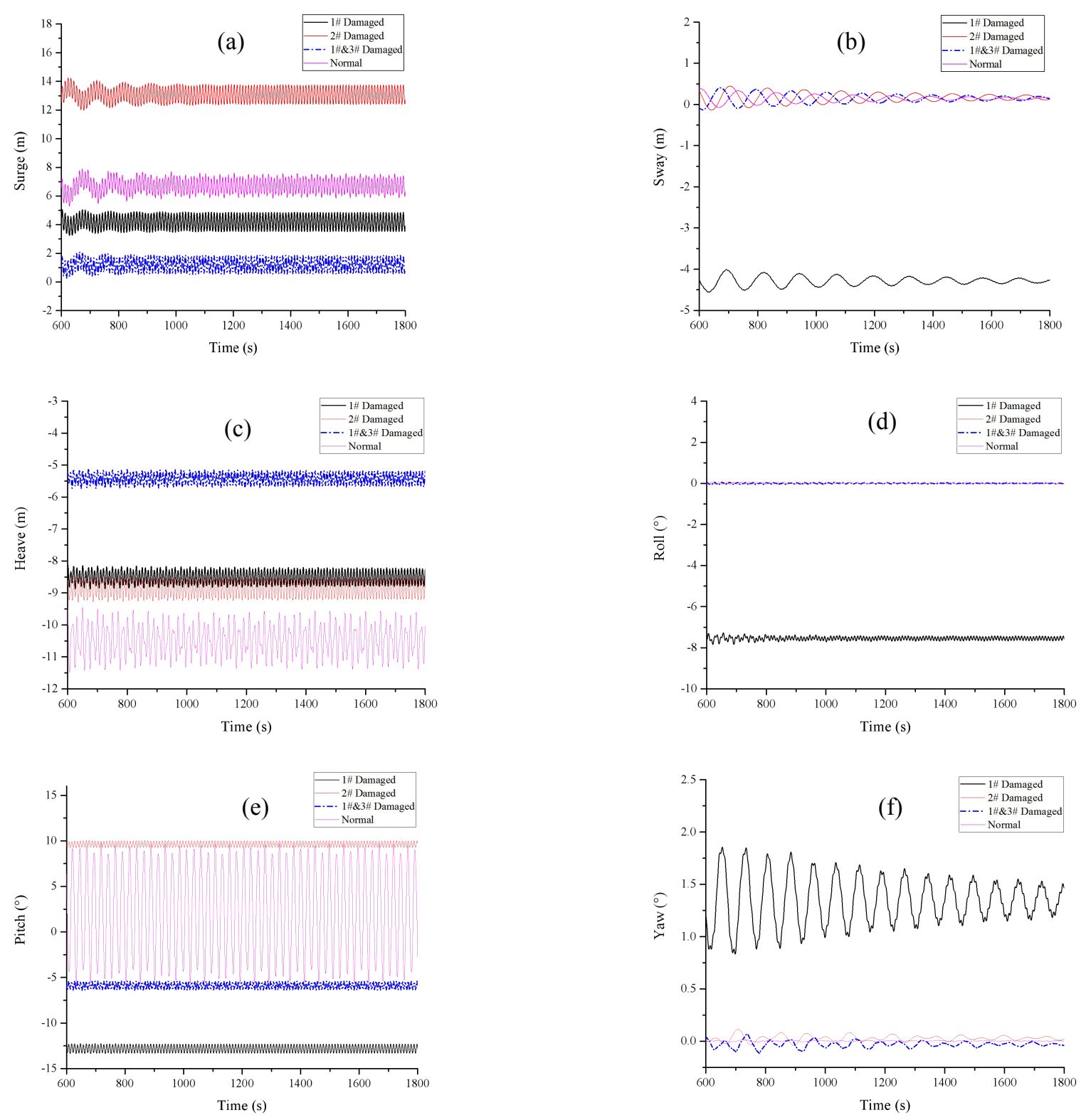

Figure 4 Dynamic motion in Load Case 1

(a) surge; (b)sway;(c) heave; (d) roll; (e)pitch; (f) yaw.

The dynamic response of six freedom motion response is shown in Figure 4. Because of the columns damaged, different types have different performance. To compare the dynamic response clearly, the analysis result is shown in Table 2 . As can be seen, the condition of 1\#damaged has a significant difference in sway, roll, pitch and yaw motions. It indicates that the column which is perpendicular to the direction of wind and wave is critical to the stability of floating platform.

Table 3 The mooring line force of OC4 semi-submersible FOWT in Load Case 1

\begin{tabular}{llcccc}
\hline & & Normal & 1\# Damaged & 2\# Damaged & 1\#\&3\# Damaged \\
\hline \multirow{2}{*}{ 1\#Mooring } & Mean $(\mathrm{kN})$ & $8.96 \mathrm{E}+02$ & $9.24 \mathrm{E}+02$ & $8.79 \mathrm{E}+02$ & $9.09 \mathrm{E}+02$ \\
& Maximum $(\mathrm{kN})$ & $9.54 \mathrm{E}+02$ & $9.50 \mathrm{E}+02$ & $9.07 \mathrm{E}+02$ & $9.34 \mathrm{E}+02$ \\
\multirow{2}{*}{ 2\#Mooring } & Mean $(\mathrm{kN})$ & $1.43 \mathrm{E}+03$ & $1.61 \mathrm{E}+03$ & $1.59 \mathrm{E}+03$ & $1.59 \mathrm{E}+03$ \\
& Maximum $(\mathrm{kN})$ & $1.66 \mathrm{E}+03$ & $1.70 \mathrm{E}+03$ & $1.69 \mathrm{E}+03$ & $1.67 \mathrm{E}+03$ \\
\multirow{2}{*}{ \#\#Mooring } & Mean $(\mathrm{kN})$ & $9.05 \mathrm{E}+02$ & $9.49 \mathrm{E}+02$ & $8.89 \mathrm{E}+02$ & $9.17 \mathrm{E}+02$ \\
& Maximum $(\mathrm{kN})$ & $9.68 \mathrm{E}+02$ & $9.74 \mathrm{E}+02$ & $9.16 \mathrm{E}+02$ & $9.39 \mathrm{E}+02$ \\
\hline
\end{tabular}


The result of mooring lines tension in Case 1 is shown in Table 3. In the condition that $1 \#$ Damaged, the tension of all moorings is increasing. Compared to Normal, the average tension of 1\#mooring, 2\#mooring and 3\#mooring increase by 3.09\%, $12.08 \%$ and $4.94 \%$. This result also indicates $2 \#$ mooring line is the main-bearing cable chain and 1\#Damaged incite a significant load on it.

\section{Load Case 2: unsteady wind and irregular wave sea condition}

To test the columns damaged influence of OC4 DeepCwind semi-submersible floating offshore wind turbine in real sea condition, the performance of it in operational sea condition should be investigated. The JONSWAP spectra with a default peak parameter $\gamma$ value of 3.3 is used to describe the character of irregular wave which the significant wave height (Hs) is $3 \mathrm{~m}$ and the spectral period is $10 \mathrm{~s}$. The wind turbine works in its rated power while the mean wind speed is $11.4 \mathrm{~m} / \mathrm{s}$ based on IEC Kaimal wind model [10].According to TurbSim User's Guide, the " $A$ " category which is the most turbulent is selected to calculate the turbulence intensity $(\mathrm{TI}=0.16)$.

Table 4 The dynamic motion response of OC4 semi-submersible FOWT in Load Case 2

\begin{tabular}{llcccc}
\hline & & Normal & 1\# Damaged & 2\# Damaged & 1\#\&3\# Damaged \\
\hline \multirow{5}{*}{ Surge } & Maximum $(\mathrm{m})$ & 12.26 & 6.70 & 17.05 & 5.40 \\
& Minimum(m) & -0.12 & -2.64 & 6.40 & -6.66 \\
& STD & 1.85 & 1.46 & 1.75 & 1.91 \\
& Maximum(m) & 1.54 & -3.66 & 1.88 & 1.75 \\
& Minimum(m) & -0.68 & -4.89 & -1.04 & -0.88 \\
& STD & 0.43 & 0.16 & 0.51 & 0.52 \\
& Maximum $(\mathrm{m})$ & -8.70 & -7.19 & -6.79 & -2.72 \\
Heave & Minimum(m) & -12.68 & -9.83 & -10.73 & -7.76 \\
& STD & 0.58 & 0.35 & 0.48 & 0.67 \\
& Maximum $\left(^{\circ}\right)$ & 0.15 & 2.16 & 0.10 & 0.51 \\
& Minimum $\left(^{\circ}\right)$ & -0.13 & -16.73 & -0.06 & -0.52 \\
& STD & 0.06 & 2.48 & 0.02 & 0.19 \\
& Maximum $\left(^{\circ}\right)$ & 13.02 & -4.94 & 19.96 & 6.39 \\
& Minimum $\left(^{\circ}\right)$ & -9.42 & -21.66 & -4.00 & -19.61 \\
& STD & 3.25 & 2.31 & 2.84 & 3.46 \\
& Maximum $\left(^{\circ}\right)$ & 0.04 & 3.84 & 0.34 & 0.31 \\
Yaw & Minimum $\left(^{\circ}\right)$ & -0.03 & -1.71 & -0.22 & -0.52 \\
& STD & 0.01 & 0.76 & 0.09 & 0.15 \\
\hline
\end{tabular}

In this case, the result of the dynamic motion response is shown in Figure 5 and Table 4. As can be seen, the influence of 1\#Damaged is mainly reflected in sway, roll, pitch and yaw motion. The response of 2\#Damaged is violent and it causes the acceleration of nacelle increasing and affect the operation of wind turbine severely. Compared with 1\#Damaged, the dynamic response of 2\#Damaged and 1\#\&3\#Damaged is smaller.

The dynamic of mooring lines force is shown in Figure 6 and Table 5. In the condition of 1\#Damaged, the tension of both $3 \#$ mooring line and $1 \#$ mooring line appears the maximum value. Compared with Normal, the value increases by $8 \%$ and $11 \%$. As for $2 \#$ mooring line force, which is main stress bearing line, the maximum tension of it is in $1 \# \& 3 \#$ Damaged and the value is $2310 \mathrm{kN}$. It increases by $15 \%$ to Normal. 


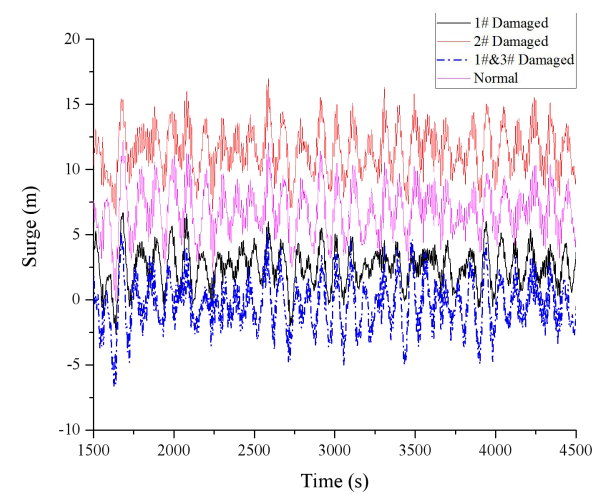

(a)

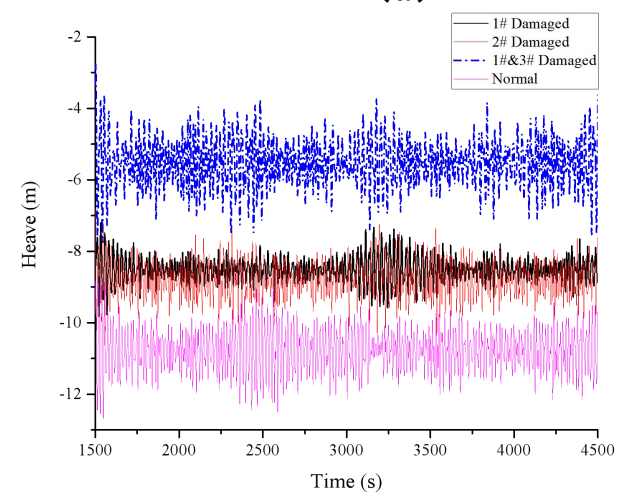

(c)

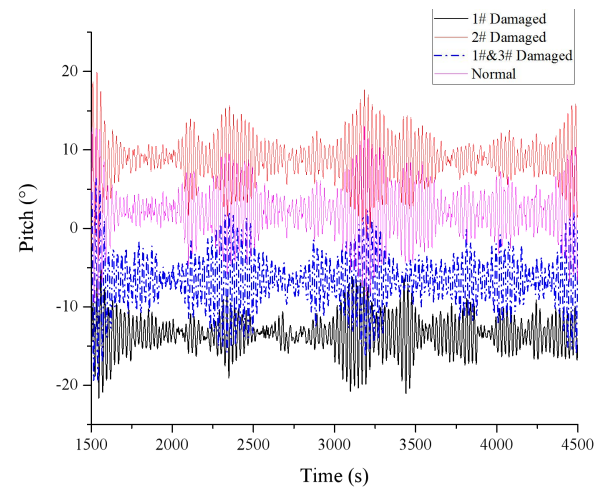

(e)

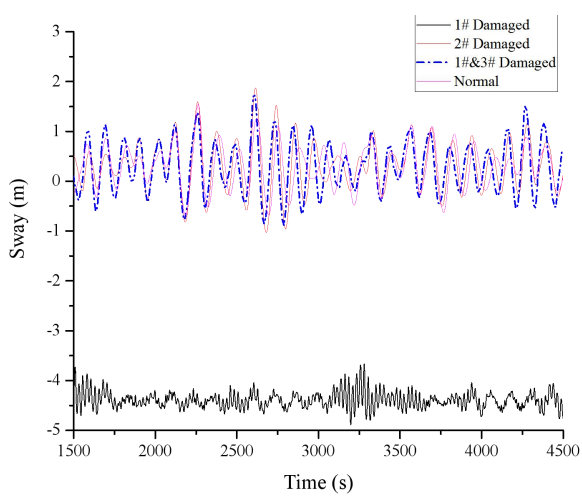

(b)

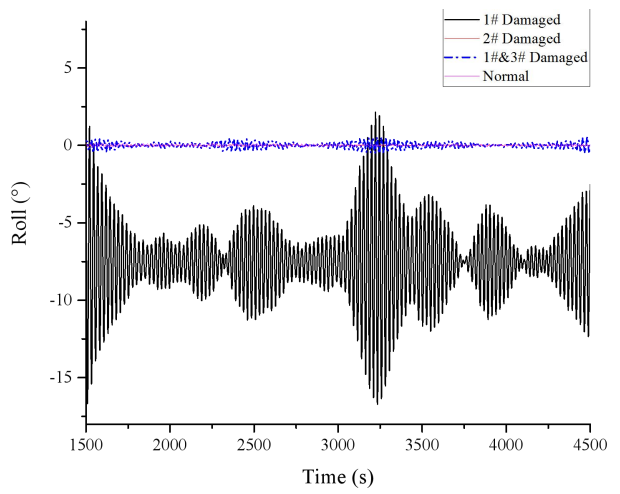

(d)

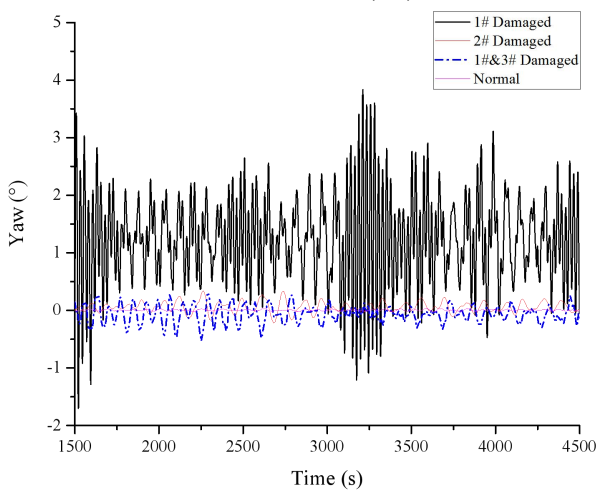

(f)

Figure 5 Dynamic motion in Load Case 2

(a) surge; (b) sway;(c) heave;(d) roll; (e) roll; (e)pitch; (f) yaw.

Table 5 The mooring line force of OC4 semi-submersible FOWT in Load Case 2

\begin{tabular}{llcccc}
\hline & & Normal & 1\# Damaged & 2\# Damaged & 1\#\&3\# Damaged \\
\hline \multirow{3}{*}{ 1\#Mooring } & Mean $(\mathrm{kN})$ & $8.88 \mathrm{E}+02$ & $9.62 \mathrm{E}+02$ & $9.04 \mathrm{E}+02$ & $9.34 \mathrm{E}+02$ \\
& Maximum $(\mathrm{kN})$ & $1.07 \mathrm{E}+03$ & $1.17 \mathrm{E}+03$ & $1.03 \mathrm{E}+03$ & $1.08 \mathrm{E}+03$ \\
& STD & $3.88 \mathrm{E}+01$ & $3.57 \mathrm{E}+01$ & $3.71 \mathrm{E}+01$ & $3.93 \mathrm{E}+01$ \\
& Mean $(\mathrm{kN})$ & $1.44 \mathrm{E}+03$ & $1.48 \mathrm{E}+03$ & $1.47 \mathrm{E}+03$ & $1.48 \mathrm{E}+03$ \\
\multirow{2}{*}{ 3\#Mooring } & Maximum $(\mathrm{kN})$ & $2.00 \mathrm{E}+03$ & $1.93 \mathrm{E}+03$ & $2.10 \mathrm{E}+03$ & $2.31 \mathrm{E}+03$ \\
& STD & $1.56 \mathrm{E}+02$ & $1.20 \mathrm{E}+02$ & $1.60 \mathrm{E}+02$ & $1.75 \mathrm{E}+02$ \\
& Mean $(\mathrm{kN})$ & $9.06 \mathrm{E}+02$ & $9.80 \mathrm{E}+02$ & $9.23 \mathrm{E}+02$ & $9.52 \mathrm{E}+02$ \\
& Maximum $(\mathrm{kN})$ & $1.06 \mathrm{E}+03$ & $1.18 \mathrm{E}+03$ & $1.11 \mathrm{E}+03$ & $1.12 \mathrm{E}+03$ \\
& STD & $3.92 \mathrm{E}+01$ & $4.07 \mathrm{E}+01$ & $4.19 \mathrm{E}+01$ & $4.34 \mathrm{E}+01$ \\
\hline
\end{tabular}




\section{Conclusions}

In this paper, three different types of base column damaged are simulated. A comparison of six freedom degree motion and mooring line force to Normal has been done above. The result can be summarized as follows:
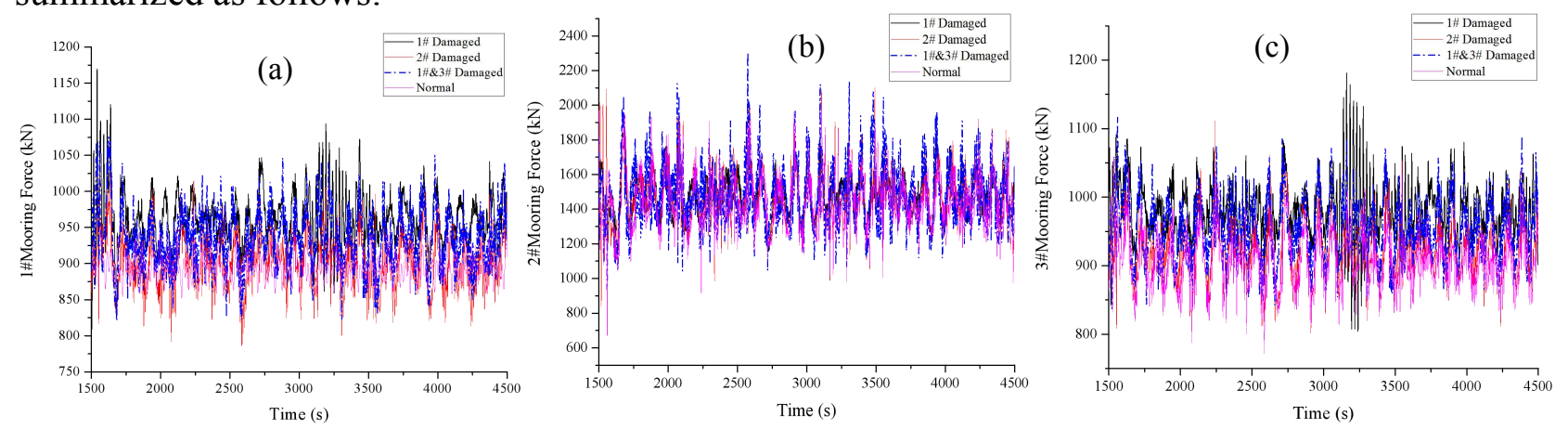

Figure 6 The dynamic response of mooring lines force in Load Case 2

(a) 1\#mooring line force; (b) 2\#mooring line force; (c) 3\#mooring line force.

$1 \#$ base column damaged has a vital effect on platform stability, especially in roll and yaw motion. It can be seen that the safety of $1 \#$ base column is important to the operation of the whole semi-submersible floating wind turbine. As the main stress-bearing mooring line, 2\# mooring line plays an important role and the strength of it is advised to be improved.

\section{Acknowledgement}

The authors would like to gratefully acknowledge financial support from the National Natural Science Foundation of China (Grant No. 51709039, 51709040). This work is also partially supported by the international collaboration and exchange program from the NSFC-RCUK/EPSRC with grant No. 51761135011 and supported by the Key Laboratory of Ocean Energy Utilization and Energy Conservation of Ministry of Education.

\section{References}

[1] D.Roddier, C.Cermelli, A.Weinstein: Proceedings of the ASME 2009 28th International Conference on Ocean, Offshore and Arctic Engineering (OMAE2009, USA 2009).

[2] C. Luan, Z. Gao and T. Moan: Proceedings of the ASME 2016 35th International Conference on Ocean, Offshore and Arctic Engineering (OMAE2016, South Korea 2016).

[3] F. Huijs: Proceedings of the ASME 2015 34th International Conference on Ocean, Offshore and Arctic Engineering (OMAE2015, Canada 2015).

[4] L.Deng, Z.Xiao, B.Wang, X. Song and H. Wu: J. Harbin Eng. Univ., Vol.37 (2016), p 1359-1365

[5] H. Wu, J. Jiang, J. Zhao and X. Ye: Appl. Mech. Mater., Vol.260-261 (2012), p 273-278

[6] W. Li, R. Ji, T. Huang: OCEANS 2016 (Institute of Electrical and Electronics Engineers, USA 2016).

[7] L. Zhang, H. Deng: Appl. Sci. Technol., Vol.38 (2011), p 13-17

[8] J. Abelson, F. Elfotouh, F. Elfotouh, F. Abulfotuh and J. Abushama: Technical Report NREL/TP-5000-60601 (National Renewable Energy Laboratory, USA 2014).

[9] J. Jonkman, S. Butterfield W. Musial and G. Scott: Technical Report NREL/TP-500-38060 (National Renewable Energy Laboratory, USA 2009).

[10] A. Robertson, J. Jonkman, M. Masciola, H. Song and A. Goupee: Technical Report NREL/TP-xxx-xxxx (National Renewable Energy Laboratory, USA 2012).

[11] R. Manhar, I. Nikolaos: Springer Handbook of Ocean Engineering (Springer Nature, Germany 2016). 